Supplementary information

\title{
Reversible Gelation Model Predictions of the Linear Viscoelasticity of Oligomeric Sulfonated Polystyrene Ionomer Blends
}

\author{
Chongwen Huang ${ }^{\dagger}$, Chao Wang ${ }^{\dagger}$, Quan Chen ${ }^{\dagger *}$, Ralph H. Colby" ${ }^{\Perp}$ R. A. Weiss ${ }^{\dagger *}$ \\ ${ }^{\dagger}$ Department of Polymer Engineering, University of Akron, Akron, OH 44325 \\ ${ }^{\star}$ State Key Laboratory of Polymer Physics and Chemistry, Changchun Institute of \\ Applied Chemistry, Chinese Academy of Sciences, Changchun 130022 China \\ "Department of Materials Science and Engineering, The Pennsylvania State University, \\ University Park, PA 16802
}

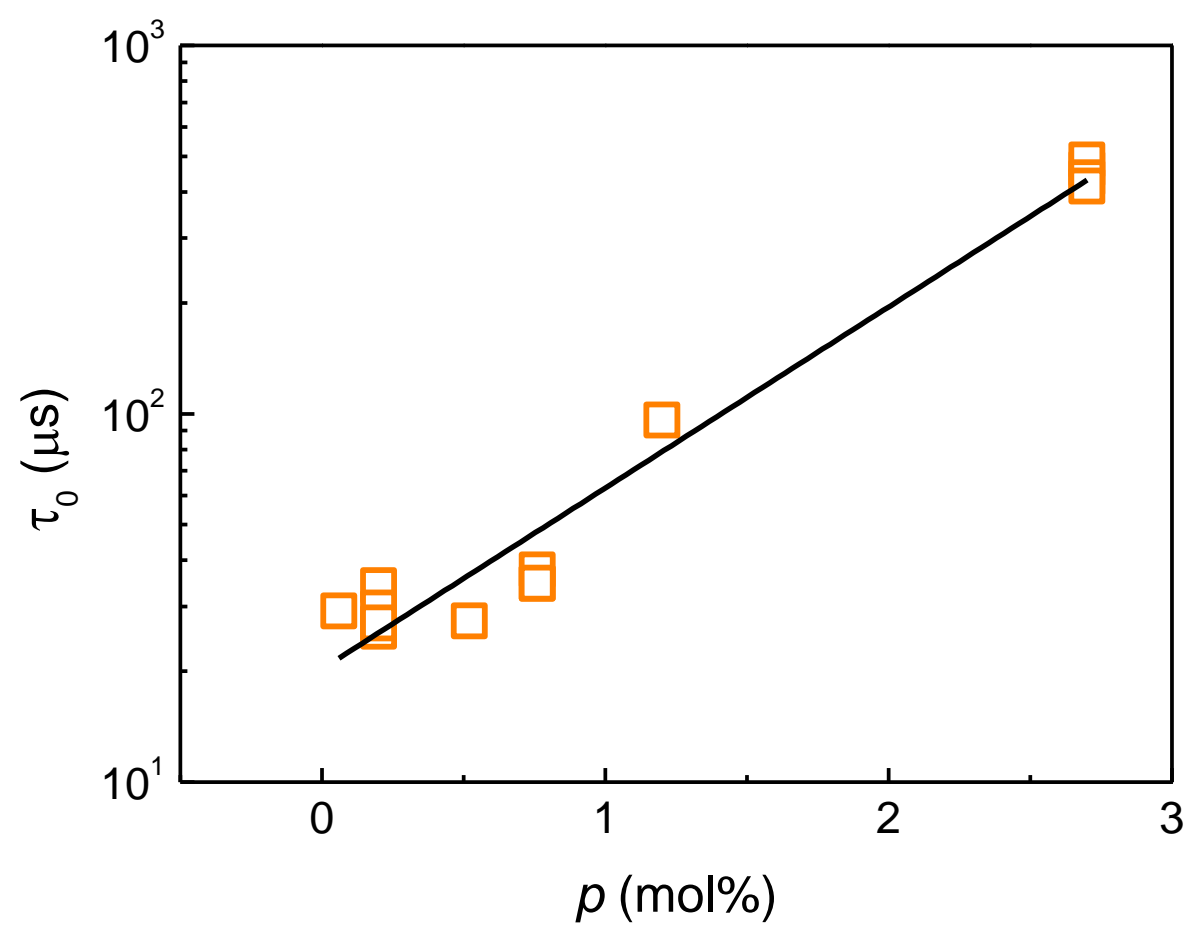

Figure S1. Relation between $\tau_{0}$ and $p$ for all SPS13.5 ionomers with each point denotes one sample. The solid line shows the linear fit with equation $\log \tau_{0}(\mu \mathrm{s})=1.3+0.49 p$. 


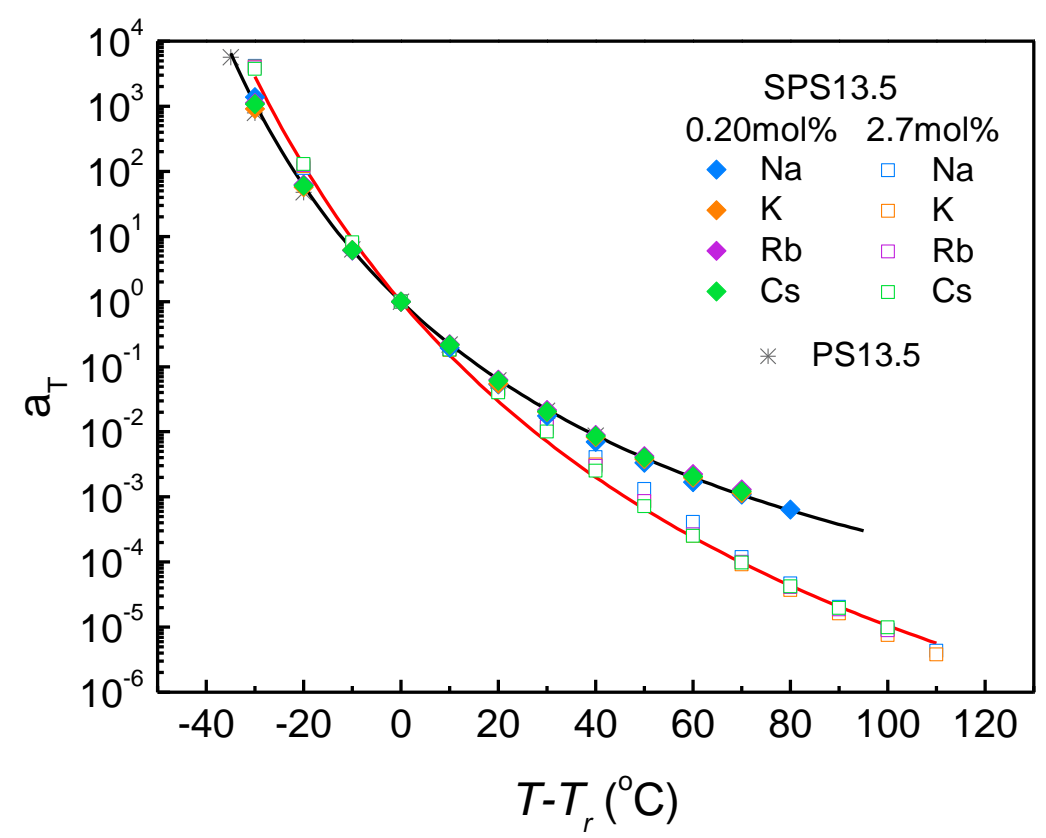

Figure S2. Temperature dependence of the experimental shift factors $\left(a_{T}\right)$ for SPS-0.20 and SPS-2.7 ionomers, where the reference temperature, $T_{r}$, was $140^{\circ} \mathrm{C}$. The black and red solid lines are the least-square fit of WLF equation for SPS-0.20 and SPS-2.7, respectively.

Table S1. WLF Constants for PS13.5, SPS-0.20, SPS-2.7 ionomers.

\begin{tabular}{lcccccccccc}
\hline & \multicolumn{3}{c}{ SPS-0.20 } & \multicolumn{5}{c}{ SPS-2.7 } \\
\hline & $\mathrm{PS13.5}$ & $\mathrm{Na}$ & $\mathrm{K}$ & $\mathrm{Rb}$ & $\mathrm{Cs}$ & $\mathrm{Na}$ & $\mathrm{K}$ & $\mathrm{Rb}$ & $\mathrm{Cs}$ \\
\hline $\mathbf{C}_{\mathbf{1}}$ & 7.5 & 7.3 & 7.5 & 7.1 & 7.2 & 11.3 & 11.7 & 11.3 & 11.2 \\
\hline $\mathbf{C}_{\mathbf{2}}(\mathbf{K})$ & 106.5 & 99.9 & 105.4 & 99.2 & 101.2 & 130.1 & 132.4 & 127.7 & 126.7
\end{tabular}

